\title{
Acute Pyelonephritis: The Clot Unfolds, Evidence than Supports Complex Nature of the Renal Vein Thrombosis; Therapeutical Implications
}

\author{
Luis Javier Flores Alvarado', Sergio Alberto Ramirez Garcia² and Gerardo Candelario Mejía ${ }^{3}$ \\ ${ }^{1}$ Laboratorio de Bioquímica, Departamento de Biología Molecular y Genómica, Centro Universitario de Ciencias de la Salud (CUCS), Benemérita Universidad de \\ Guadalajara. Jalisco, México \\ ${ }^{2}$ Instituto de Investigaciones sobre la Salud Pública, Universidad de la Sierra Sur, Sistema de Universidades Estatales de Oaxaca. Oaxaca, México \\ ${ }^{3}$ Programa de Doctorado en Ecofisiología Vegetal y Recursos Genéticos, Centro Universitario de Ciencias Biológico Agropecuarias (CUCBA) de la Benemérita \\ Universidad de Guadalajara. Jalisco, México
}

\section{Description}

The recent case published on Renal Vein Thrombosis (RVT) due to acute pyelonephritis (APN) is an important contribution to the clinical management of thrombophilia [1-3]. Considering that acute pyelonephritis is not contemplated as a common cause of renal RVT and inferior vena cava thrombosis (IVCT), but not an uncommon condition amongst patients with nephrotic syndrome (NS) and commonly seen in patients with membranous glomerulonephritis [4], requires that physicians take into consideration genetic causes and other risk factors that leads to thrombophilia. Previously, the association of RVT with acute pyelonephritis was reported in probands with sepsis plus trombotic risk factor as can be seen in hyperhomocysteinemia or diabetes mellitus [4-7]. In order to explain the physiopathology of RVT seen ocassionaly in patients with pyelonephritis it is important to explore the possibility of hyperhomocysteinemia in the case described by Talwar et al., who had diabetes but without sepsis. Nevertheless that possibility was not studied. This is important, because, in addition to the well clinical and conservative management, carried out by the authors, they could be used supplements of B complex and folic acid in order to handle the possible hyperhomocysteinemia reported by Kumar et al. This condition cannot be excluded from the evidence presented in the paper $[1,5]$. Detection of homocysteine, or preventive treatment with folic acid is crucial because it reduces the risk, by $10 \%$ to $20 \%$, of venous thrombosis [8]. Besides reducing risk of thrombophilia, patient, without any surgical interventions, must be treated with antibiotics and anticoagulation therapy. It's obvious that the clinical response in RVT is influenced by other factors, including genetic and environmental factors. Thrombophilia not only is a polygenic trait, but also a multifactorial disease that can be modulated by environmental factors. So it is important to carry out the screening of genetic causes of thrombophilia in order to establish a better therapeutic decision and a personalized therapy, which were not analyzed in the case report published by Talwar. The most important causes of thrombofilia are mutation in Factor V Leiden, (FVL, G1691), MTHFR, and prothrombin genes. This mutation was reported previously in patients with thrombosis related to idiopathic NS [9]. Therefore, when thrombofilia is present in rare combination, as the one reported in the patient of Talwar, it is imperative to consider the genetic mechanisms of thrombosis, its progression and its therapeutic interventions. Also we must investigate the correlation of thrombofilia with development of bilateral RVT, as well as the interaction with environmental factors such as infections. In some cases the mutations are determinant of clinical phenotype; the multigenic thrombophilia is associated with massive IVCT, NS and chronic bilateral pulmonary artery thromboembolism $[9,10]$. There are cases of unilateral RVT that are associated with SERPINE1 4G, FVL, heterozygous of MTHFR-677T, MTHFR-1298C gene mutations. The combinations of these entities increase the likelihood of a thrombotic event $[11,12]$.

Another important variable to consider in the treatment and clinical management of RVT is the age of onset; no studies in this regard have been reported yet, but evidence of spontaneous thrombosis is present in probands with (TVS) where the FVL (OR 4.55, age 0-17, media range 2 years) mutation is the most common prothrombotic risk factor responsible for TVS during infancy and early childhood. In contrast, the PT (G20210A) (OR 2.96, average age 16 years) variant is likely to be more important during puberty and adolescence [13]. In a cross sectionally study in children's with Abdominal venous thrombosis (RVT) the following mutations was found; FVL in 14/31 babies, FVL heterozygous 9/31, while MTHFR TT677 2/31 infants, PC (protein C) type I deficiency in $2 / 31$ patients, AT (anti-thrombin) deficiency in $1 / 31$ patients. In contrast, the protein S (PS) deficiency was not found in RVT [14]. Most of these patients can be treated with recombinant tissue plasminogen until complete thrombus dissolution [15]. But unfortunately, those studies lack molecular screening for mutations in genes related to thrombophilia, in adult probands with RVT, as in the case reported by Talwar et al.. We believe that the authors published the results of these studies as part of another manuscript, and therefore they only focused on the clinical management of the proband.

We consider that it is important to report the molecular studies in patients who had a family history of thrombophilia like the index case reported by Talwar. Recently, a cross sectionally study in children with high prevalence of cerebral venous sinus thrombosis (CVST) showed four new mutations as thrombophilic factors, p.N93Y, p.L251P, p.D281V and c.829-2A>T, in Human cystathionine beta-synthase (CBS) gene. These mutations are very important because they are predictive of complete responsive to treatment with pyridoxine $(7.7 \%)$, in partial responsive $53.9 \%$ probands. The mutations in CBS also are associated with the vascular presentation or thromboembolic events of the CVS. CBS mutations gene as well as thromboembolic events and therapy with pyridoxine and his association with APN must be analyzed in RVT [16]. It would be worthwhile to analyze the response to clinical treatment of thrombophilia, the endothelial nitric oxide synthase gene, intron 4 (VNTR) polymorphism, because the variable number tandem repeat of this VNTR is linked with the pathogenesis of vascular grafts thrombosis in patients undergoing hemodialysis [17].

*Corresponding author: Sergio Alberto Ramirez Garcia, University of the Southern Highlands, Guillermo Rojas Mijangos Street S / N, Esq. Av. Universidad Col. Ciudad Universitaria, Miahuatlán of Porfirio Diaz, Oaxaca, Mexico CP 70800, Tel: +1951573141 0; E-mail: sergio7genetica@Hotmail.com

Received May 23, 2015; Accepted August 18, 2015; Published August 27, 2015 Citation: Alvarado LJF, Garcia SAR, Mejía GC (2015) Acute Pyelonephritis: The Clot Unfolds, Evidence than Supports Complex Nature of the Renal Vein Thrombosis; Therapeutical Implications. Brain Disord Ther 4:180. doi:10.4172/2168975X.1000180

Copyright: (c) 2015 Alvarado LJF, et al. This is an open-access article distributed under the terms of the Creative Commons Attribution License, which permits unrestricted use, distribution, and reproduction in any medium, provided the original author and source are credited. 
We agree with Talwar et al., that APN was an environmental factor determining the RTV, since it is related with inflammation as a prothrombotic factor. The evidence of elevated levels of C-reactive protein (CRP), presented in that case, generates a procoagulant environment. The endothelial dysfunction increases the expression of tissue factor cogulation, activates the opsonization, increase the generation of cytokines, adhesion molecules and promotes chemotaxis. Also, endothelia dysfunction is related with the release of inflammation mediators like tumor necrosis factor (TNF), endotoxin, heparin, alpha-1-antitrypsin and thrombomodulin, inhibitor plasminogen1(PAI-1). These events are associated with an infection of gram negative bacteria, like Escherichia coli presented in the proband [17]. It is noteworthy that not only thrombophilia is associated with infectious process, but also platelet activation with leukocyte recruitment and activation of circulating endothelial and smooth muscle cells through amplification of the inflammatory process also contributes to it. The interaction between platelets and various cytokines release chemical mediators such as IL-6, RANTES and CD40L, acting on circulating mononuclear cells are involved in the pathogenesis of thrombosis [17] The endothelial cell secretes interleukin 1-B, which activates endothelial cell generation promoting chemotaxis, adhesion, cell migration, thrombosis and proteolysis at the site of tissue damage [17]. The expression of multiple receptors related to innate and acquired platelet membrane immune response may explain the connection between the proposed thrombotic and inflammatory event in the genesis of atherosclerosis. These receptors are P-selectin, ligand (PSGL1 ), integrins as $\alpha \mathrm{II} \beta 3$ (receptors for collagen, von Willebrand factor, fibronectin and fibrinogen), adhesion molecules such as ICAM-2, Tolllike receptors as well as protease activated receptor (PAR-1 receptor establishing for thrombin), CD40 and chemokine receptors [17]. Activation of predominantly $\mathrm{T}$ lymphocyte response inflammation by helper 1 (Th1), macrophages and endothelial cells increases proteases synthesis and adhesion molecules promoting thrombus formation [17]. Finally, other environmental factors in RTV, such as autoimmunity associated with the presence of antiphospholipid antibodies directed against annexin V, anti cardiolipin antibodies, anti- $\beta 2$-glucoproteín, and antibodies such as antiprothrombin must be investigated. They are part of laboratory findings in antiphospholipid syndrome which is the most frequent cause of acquired thrombophilia. Also this syndrome represents $70 \%$ of the venous thrombotic events. This and other environmental causes of thrombophilia such as lupus and vasculitis were discarded by Talwar et al. [17]. Anticardiolipin antibodies are a heterogeneous group of antibodies against epitopes. The main epitope is located in domain I which binds B2-GPI in the lysine near 43. The B2-GPI has little affinity for anionic phospholipids, the formation of antibody-B2-GPI increases affinity for anionic phospholipids more than 100 times, and this complex is able to interfere with the binding of clotting factors at the catalytic surface of phospholipids [17]. It is postulated that antigenicity is generated through a mechanism called endogenous immunogenic adjuvant [17]. The presence of lupus anticoagulant positive-dependent anti-B2/GPI is associated with thromboembolic complications. Prothrombin is a cofactor of a lupus anticoagulant factor. The encrypted antiprothrombin antibodies recognize exposed epitopes when prothrombin joins phospholipids. ATP prolongs of clotting times, either by inhibiting the conversion of prothrombin to thrombin (hypoprothrombinemia) or increasing the clearance of complex anti-PT-prothrombin from circulation, but more studies are needed about it [17].

Besides the clinical management of RTV and other diseases with thrombosis in the post genomic era, physician must think about the polymorphism described in this paper as a possible causes, and perform the molecular screening, of thrombophilia, especially when uncommon association like the Talware et al. case is observed; pyelonephritis. It should be noted that non-infectious inflammation is a risk factor for thrombosis. Treatment involves anticoagulation therapy and the duration of treatment depends on the precipitating cause and patient adherence to treatment. Thrombolysis and surgical treatment is rarely indicated, but it must be considered; anticoagulation and conservative management like the one conducted by Talware et al. case must be considered in the management of similar clinical cases. In conclusion, APN requires further evidence that supports the multifactorial nature of the thrombosis as well as RTV. The RTV is a very important condition yet overlooked so we should always keep in mind in order to prevent it.

\section{References}

1. Talwar A, Kavidasan A, Randhawa R, Bhattacharya M, Somani V, et al. (2014) Acute Pyelonephritis: The clot unfolds. J Clin Case Rep 4: 381.

2. Lee K, Kim A, Lee SY, Jung JH, Kim M, et al. (2009) Acute Pyelonephritis Complicated by Renal Vein Thrombosis and Pulmonary Embolism in Patient without any Thrombotic Risks. Infect Chemother 41: 293-297.

3. Bassilios N, Tassart M, Restoux A, Bigot JM, Rondeau E, et al. (2004) Inferior vena cava thrombosis due to acute pyelonephritis. Nephrol Dial Transplant 19 981-983.

4. Kumar S, Singh SK, Mavuduru RS, Acharya NC, Agarwal MM, et al. (2009) Acute pyelonephritis with renal vein and inferior vena cava thrombosis in a case of hyperhomocysteinemia. Int Urol Nephrol 41: 185-188.

5. Harris LA, Van E MJ, Fundell LJ (2012) Acute bilateral renal vein thrombosis secondary to sepsis from pyelonephritis. Int Braz J Urol 38 132-134.

6. Hotoleanu C, Porojan-Luga M, Rusu ML, Andercou A (2007) Hyperhomocysteinemia: clinical and therapeutical involvement in venousthrombosis. Rom J Intern Med 45: 159-164.

7. Sahin M, Ozkurt S, Degirmenci NA, Musmul A, Temiz G, et al. (2013) Assessment of genetic risk factors for thromboembolic complications in adults with idiopathic nephrotic syndrome. Clin Nephrol 79: 454-462.

8. Blagova OV, Dzemeshkevich SL, Kozlovskaia NL, Nedostup AV, Sarkisova ND, et al. (2012) Successful treatment of massive thrombosis of the vena cava inferior with nephrotic syndrome and chronic bilateral pulmonary artery thromboembolism in a patient with genetic thrombophilia. Ter Arkh 84: 41-47.

9. Cinemre $\mathrm{H}$, Bilir C, Akdemir N (2010) Isolated renal vein thrombosis associated with MTHFR-1298 and PAI-1 4G gene mutations. Clin Appl Thromb Hemost 16: $708-710$

10. Sandal G, Arıkan E, Kuybulu AE, Ormecı AR (2014) Unilateral Renal Vein Thrombosis and Adrenal Hemorrhage in A Newborn with Homozygous Factor V Leiden and Heterozygous Of MTHFR-677T, MTHFR-1298C Gene Mutations. Indian J Hematol Blood Transfus 30: 294-298.

11. Schobess R, Junker R, Auberger K, Münchow N, Burdach S, et al. (1999) Factor V G1691A and prothrombin G20210A in childhood spontaneous venousthrombosis--evidence of an age-dependent thrombotic onset in carriers of factor V G1691A and prothrombin G20210A mutation. Eur J Pediatr 158: S105-S108.

12. Heller C, Schobess R, Kurnik K, Junker R, Günther G, et al. (2000) Abdomina venous thrombosis in neonates and infants: role of prothrombotic risk factors-a multicentre case-control study. For the Childhood Thrombophilia Study Group. Br J Haematol 111: 534-539.

13. Giordano P, Laforgia N, DiGiulio G, Storelli S, Mautone A, et al. (2001) Rena vein thrombosis in a newborn with prothrombotic genetic risk factors. J Perinat Med 29: 163-166.

14. Karaca M, Hismi B, Ozgul RK, Karaca S, Yilmaz DY, et al. (2014) High prevalence of cerebral venous sinus thrombosis (CVST) as presentation of cystathionine beta-synthase deficiency in childhood: molecular and clinical findings of Turkish probands. Gene 534: 197-203. 
Citation: Alvarado LJF, Garcia SAR, Mejía GC (2015) Acute Pyelonephritis: The Clot Unfolds, Evidence than Supports Complex Nature of the Renal Vein Thrombosis; Therapeutical Implications. Brain Disord Ther 4:180. doi:10.4172/2168-975X.1000180

Page 3 of 3

15. Basaran O, Atac FB, Karakayali F, Aliosmanoglu I, Yagmurdur MC, et al. (2007) Endothelial nitric oxide synthase gene intron 4 (VNTR) polymorphism and vascular access graft thrombosis. J Invest Surg 20: 49-53.
16. Majluf-Cruza A, Espinosa-Larrañaga $F$ (2007) Fisiopatología de la thrombosis Gac Méd Méx 143: S11-S14.

17. Rubio JB, Salazar-Paramo M, Nava A (2012) Aspectos básicos sobre trombofilia, inflamación y autoinmunidad. El Residente 1: 16-20. 